\title{
Refining the Interpretation of NIR Band Shapes in a Polyynediyl Molecular \\ Wire
}

\section{Matthias Parthey, ${ }^{[a]}$ Josef B. G. Gluyas, ${ }^{[b]}$ Phil A. Schauer, ${ }^{[b]}$ Dmitry S. Yufit, ${ }^{[b]}$ Judith A. K. Howard, ${ }^{[b]}$ Martin Kaupp* ${ }^{* a]}$ and Paul J. Low ${ }^{*[b]}$}

Dedication: Dedicated to Professor Michael I. Bruce, mentor and friend, on the occasion of his $75^{\text {th }}$ birthday.

[a] M. Parthey, Prof. Dr. M. Kaupp

Technische Universität Berlin, Institut für Chemie

Sekr. C7, Strasse des 17. Juni 135, 10623 Berlin (GER)

E-mail: martin.kaupp@tu-berlin.de

[b] Dr. J. B. G. Gluyas, Dr. P. A. Schauer, Dr. D. S. Yufit, Prof. Dr. J. A. K. Howard, Prof. Dr. P. J. Low

Durham University, Department of Chemistry

Science Site, South Road, Durham, DH1 3LE (UK)

E-mail: p.j.low@durham.ac.uk

Polyynediyl bridged systems have attracted attention for more than two decades, with early synthetic efforts complemented more recently by experimental and computational investigations of electronic structure. ${ }^{[1]}$ Polyynediyl complexes serve as models of the linear carbon allotrope carbyne, ${ }^{[2]}$ and permit investigations of intramolecular electron transfer (ET) reactions and mixed-valence (MV) characteristics. ${ }^{[1,3]}$ The highly delocalized electronic structures often associated with $\left\{L_{n} M\right\}\left\{\mu-(C \equiv C)_{n}\right\}\left\{M L_{n}\right\}$ complexes has also led to consideration of their potential applications in molecular electronics. ${ }^{[4]}$ Although impressively long polyynediyl complexes are known, ${ }^{[2]}$ the greatest concentration of work has focused on the properties of diynediyl-bridged $(\mu-C \equiv C C \equiv C) d^{6} / d^{6}$ transition metal complexes, which have been synthesized, characterized, and investigated in their various electrochemically accessible redox states. ${ }^{[1,3,5-12]}$ 
The degree of delocalization along the $\left\{L_{n} M\right\}(\mu-C \equiv C C \equiv C)\left\{L_{n}\right\}$ backbone, and hence the nature of the redox-derived products, is sensitive to the identity of the metal end-capping group. By varying the terminal cap, and thus the metal $d$-orbital / carbon $\pi$-system interactions, $\left[\left\{L_{n} M\right\}(\mu-C \equiv C C \equiv C)\left\{\mathrm{ML}_{n}\right\}\right]^{+}$complexes ranging from weakly (Class II in the Robin-Day scheme; e.g. $\left\{\mathrm{ML}_{n}\right\}=\left[\mathrm{Mo}(\right.$ dppe $\left.\left.)\left(\eta-\mathrm{C}_{7} \mathrm{H}_{7}\right)\right]\right)^{[5]}$ to strongly coupled (Class III; $\left.\left\{\mathrm{ML}_{\mathrm{n}}\right\}=\left[\mathrm{Fe}(\mathrm{dppe}) \mathrm{Cp}^{*}\right]\right)$ systems can be obtained. ${ }^{[4 \mathrm{~b}, 6,7]}$ Charge delocalization along the six-atom $\mathrm{MC}_{4} \mathrm{M}$ chain is increased in complexes of the heavier metals, $\left\{\mathrm{ML}_{\mathrm{n}}\right\}=\left[\mathrm{Ru}\left(\mathrm{PPh}_{3}\right)_{2} \mathrm{Cp}\right](\mathbf{1}),{ }^{[8]}\left[\mathrm{Ru}(\mathrm{dppe}) \mathrm{Cp}^{*}\right],{ }^{[9]}\left[\mathrm{Os}(\mathrm{dppe}) \mathrm{Cp}^{*}\right],{ }^{[10]}$ and $\left[\mathrm{Re}(\mathrm{NO})\left(\mathrm{PPh}_{3}\right) \mathrm{Cp}^{*}\right] .^{[11]}$ The increased $\mathrm{C}_{4}$-bridge $\pi$-character in the frontier molecular orbitals of these complexes suggests that descriptions in terms of metalstabilized carbon centered radicals might be more appropriate than mixed-valence classifications.

The description of the electronic structure in $\left[\left\{L_{n} M\right\}(\mu-C \equiv C C \equiv C)\left\{M L_{n}\right\}\right]^{n+}$ complexes is usually based on IR, UV-vis-NIR and EPR spectroscopic data supported by quantum chemical calculations. ${ }^{[3-14]}$ IR-active $v(C \equiv C)$ vibrations or any local auxiliary ligand modes, e.g. $v(\mathrm{NO})$ or $v(\mathrm{CO})$, can provide information about charge distribution, ${ }^{[11,15]}$ and MLCT / LMCT bands also contain useful electronic information. ${ }^{[16]}$ More commonly the lower energy (NIR) intervalence charge transfer (IVCT) bands are analyzed within the framework of the Marcus-Hush and the Mulliken-Hush theory to provide details of the underlying electronic structure. These simple but powerful 'two-state' models permit electronic coupling information to be extracted from analysis of the IVCT energy, intensity and band shape. ${ }^{[17]}$ However, the NIR spectra of MV complexes often feature complex absorption envelopes due to the partial resolution of vibrational fine structure, ${ }^{[18]}$ or multiple IVCT processes due 
to low symmetry at the metal center ${ }^{[5]}$ and / or by spin-orbit coupling in the case of complexes of the heavier metals. ${ }^{[19]}$

The compound $\left[\left\{\mathrm{Ru}\left(\mathrm{PPh}_{3}\right)_{2} \mathrm{Cp}\right\}_{2}(\mu-\mathrm{C} \equiv \mathrm{CC} \equiv \mathrm{C})\right]^{+},[1]^{+}$, is a well-known example of a highly delocalized butadiynyl-bridged bimetallic complex in which the carbon chain plays a significant role in stabilizing the unpaired electron. ${ }^{[8]}$ However, reinvestigation of the NIR spectrum of $[1]^{+}$revealed a high energy shoulder that was not included in the original analysis (Figure 1). ${ }^{[8]}$ The NIR band envelope in $[1]^{+}$is not solvatochromic (Figure S12), consistent with a highly delocalized (or strongly coupled) system. However, the two-state Hush treatment of such strongly coupled systems predicts only a single asymmetric band, ${ }^{[17-19]}$ no obvious vibrational progression fits the ca. $3000 \mathrm{~cm}^{-1}$ separation of the principal band and the shoulder, and spin-orbit splitting in $\mathrm{Ru}$ complexes is also too small (typically around 1000 $\left.\mathrm{cm}^{-1}\right)^{[19]}$ to account for the observed separation of the component bands. In this article we present an interpretation of this feature and show that the presence of rotamers is also a crucial variable that may influence the appearance of the IVCT band and the underlying electronic structure.

To provide a quantum-chemical perspective, calculations at density-functional theory (DFT) level were performed. Starting from a $C_{\mathrm{i}}$-symmetric input the structure of $\left[\mathbf{1}^{\prime}\right]^{+}$(the ' notation being employed to distinguish the in silico system from the experimental complex) was optimized without constraints using the global hybrid functional BLYP35 with a suitable continuum solvent model (dichloromethane, DCM) (this approach has been specifically developed to properly characterize class II/III border-line mixed-valence systems ${ }^{[20]}$ ). The calculated spin density in the resulting fully optimized trans- $\left[\mathbf{1}^{\prime}\right]^{+}$structure is evenly distributed over the $\mathrm{RuC}_{4} \mathrm{Ru}$ chain (see SI), whilst Mulliken population analysis of the $\alpha$-SOMO, the $\alpha$-HOMO 
and the $\beta$-HOMO show appreciable diynediyl bridge (45\%, $57 \%$ and $57 \%$, respectively) and metal character $(34 \%, 37 \%$ and $37 \%)$ in line with earlier analyses. $^{[8]}$

Time-dependent DFT (TDDFT) calculations (BLYP35/DCM) revealed a single intense $\left(\mu_{\text {trans }}=9.5 \mathrm{D}\right)$ transition at $11702 \mathrm{~cm}^{-1}$ arising from the excitation from the $\beta$ HOMO-1 to the $\beta$-SOMO. Given the distribution and nodal properties of these orbitals, this excitation is best described as a $\pi-\pi^{*}$ transition (Figure 2). As expected for transitions not involving charge transfer, the TDDFT result is in excellent agreement with the energy of the principal component of the experimentally determined spectrum at $11655 \mathrm{~cm}^{-1}$ (Figure 1). However, no significant transition in the TDDFT results could account for the higher-energy shoulder.

A number of rotamers of $\mathbf{1}$ have been observed crystallographically, ${ }^{[21]}$ prompting consideration of the influence of different conformers on the electronic structure of the ground and excited states of $[\mathbf{1}]^{+}$. To investigate the influence of different rotamers of $\left[\mathbf{1}^{\prime}\right]^{+}$on the appearance of the NIR spectrum, constrained structure optimizations with a fixed P-Ru-Ru-P dihedral angle $(\Omega)$ were performed. Starting from the optimized nearly $C_{\mathrm{i}}$-symmetric structure $\left(\Omega=180^{\circ}\right)$ the dihedral angle was decreased to $0^{\circ}$ in steps of $10^{\circ}$. Interestingly, the energy of the resulting rotational energy potential $\left(E_{\mathrm{s}}\right)$ varies by only ca. $13 \mathrm{~kJ} / \mathrm{mol}$, with the energy maximum being at $\Omega=0^{\circ}\left(\Delta E=E_{0}-E_{180^{\circ}}=12.6 \mathrm{~kJ} / \mathrm{mol}\right)$. A plot of $E_{\mathrm{a}}$ against $\Omega$ (Figure S1) revealed three minima at $\Omega=30^{\circ}(\Delta E=1.0 \mathrm{~kJ} / \mathrm{mol}) ; 110^{\circ}(\Delta E=6.9 \mathrm{~kJ} / \mathrm{mol})$ and $180^{\circ}$ (reference, $E=0$ ). These three structures were subsequently used as starting points for three full unconstrained optimizations leading to three genuinely energy-minimized conformers: the previously noted trans $-\left[1^{\prime}\right]^{+}\left(\Omega \approx 180^{\circ}, \Delta E=0\right)$, perp- $\left[1^{\prime}\right]^{+}$ $\left(\Omega \approx 112^{\circ}, \Delta E=7.5 \mathrm{~kJ} / \mathrm{mol}\right)$ and $\operatorname{cis}-\left[\mathbf{1}^{\prime}\right]^{+}\left(\Omega \approx 27^{\circ}, \Delta E=1.6 \mathrm{~kJ} / \mathrm{mol}\right)$. 
All three rotamers exhibit delocalized electronic structures with spin density distributed evenly over the six-atom $\mathrm{RuC}_{4} \mathrm{Ru}$ chain. Each structure gives a single $v(\mathrm{C} \equiv \mathrm{C})$ vibration (trans- $\left[\mathbf{1}^{\prime}\right]^{+} v(\mathrm{C} \equiv \mathrm{C})=1878 \mathrm{~cm}^{-1}$, perp $-\left[\mathbf{1}^{\prime}\right]^{+} v(\mathrm{C} \equiv \mathrm{C})=1868 \mathrm{~cm}^{-1}$, cis- $\left.\left[1^{\prime}\right]^{+} v(C \equiv C)=1871 \mathrm{~cm}^{-1}\right)$ which compares well with the broad band observed experimentally $\left(v(C \equiv C)=1855 \mathrm{~cm}^{-1}\right.$, see $\left.\mathrm{SI}\right)$. TDDFT calculations were performed for all nineteen values of $\Omega$ in the relaxed scan (SI) and for the three fully optimized structures. The fully optimized structures all exhibit an intense $\beta-\mathrm{HOMO}-1$ to $\beta$ SOMO transition near $11600 \mathrm{~cm}^{-1}[\text { trans-[1'] }]^{+}, 11702 \mathrm{~cm}^{-1}\left(\mu_{\text {trans }}=9.5 \mathrm{D}\right)$; perp- $\left[\mathbf{1}^{\prime}\right]^{+}$ $11524 \mathrm{~cm}^{-1}\left(\mu_{\text {trans }}=8.8 \mathrm{D}\right)$; $\left.\boldsymbol{c i s}-\left[\mathbf{1}^{\prime}\right]^{+} 11572 \mathrm{~cm}^{-1}\left(\mu_{\text {trans }}=9.8 \mathrm{D}\right)\right]$ with $\pi-\pi^{*}$ character as described before. The transition dipole moment reveals trends in the diynediyl contribution to the $\beta-\mathrm{HOMO}-1$ orbital (trans-[1'] $]^{+}: 19 \%$, perp- $\left[\mathbf{1}^{\prime}\right]^{+}: 16 \%$, cis-[1'] $]^{+}$: $19 \%$ ) and reflects the orbital overlap with the $\beta$-SOMO.

For perp- $\left[1^{\prime}\right]^{+}$a second, less intense excitation at $13982 \mathrm{~cm}^{-1}\left(\mu_{\text {trans }}=3.3 \mathrm{D}\right)$ arising from a $\beta$-HOMO-3 to $\beta$-SOMO transition is also calculated. This transition has no calculated intensity for trans- $\left[1^{\prime}\right]^{+}\left(\mu_{\text {trans }}=0.0 \mathrm{D}\right)$ and is only very weak in the case of $\operatorname{cis}-\left[\mathbf{1}^{\prime}\right]^{+}\left(\mu_{\text {trans }}=0.8 \mathrm{D}\right)$. The $\beta-\mathrm{HOMO}-3$ is largely metal in character $\left(\mathrm{Ru} / \mathrm{C}_{4}\right.$ / Ru: trans-[1'] $]^{+}$27\%/3\%/18\%; cis-[1'] $]^{+}$25\%/4\%/19\%; perp-[1'] $]^{+}$18\%/9\%/27\%), and the $\beta$-HOMO-3 to $\beta$-SOMO transition only gains appreciable intensity when there is appreciable spatial overlap between these orbitals (i.e. in perp- $\left[\mathbf{1}^{\prime}\right]^{+}$, Figure 3). Very similar results have been obtained for two conformational isomers of the ethynediyl complex $\left[\{\mathrm{Ru}(\mathrm{dppe}) \mathrm{Cp}\}_{2}(\mu-\mathrm{C} \equiv \mathrm{C})\right]^{+}$although in this case the greater steric congestion around the $\mathrm{C}_{2}$ bridge gives rise to a greater energy barrier to rotation. ${ }^{[22]}$ The higher-energy shoulder in $[\mathbf{1}]^{+}$is therefore assigned to an MLCT transition that 
gains intensity in rotameric forms with approximately orthogonal disposition of the $\mathrm{Cp}$ rings around the $\mathrm{RuC}_{4} \mathrm{Ru}$ axis.

Thus, all of the computational structures of $[1]^{+}$show a lower-energy transition in a narrow range around $11700 \mathrm{~cm}^{-1}$ and higher-energy transition around $14300 \mathrm{~cm}^{-1}$ (SI). The excitation near $11700 \mathrm{~cm}^{-1}$ exhibits significant intensity for all rotamers $\left(\mu_{\text {trans }} \geq 8.4 \mathrm{D}\right)$. In contrast, the transition dipole moment of the higher-energy transition, which correlates with the shoulder in the experimental spectrum (Figure 1), steadily gains intensity from $\Omega=0^{\circ}\left(\mu_{\text {trans }}=0.8 \mathrm{D}\right)$ to $\Omega=100^{\circ}\left(\mu_{\text {trans }}=3.8 \mathrm{D}\right)$, and $\mu_{\text {trans }}$ decreases gradually when advancing towards $\Omega=180^{\circ}(0.0 \mathrm{D})$.

To test the quantum-chemically predicted importance of rotamers for the shape of the NIR band of mixed-valence systems a conformationally restricted diynediyl complex comparable to $\mathbf{1}$ was required. Gladysz and colleagues have used $\alpha, \omega$ bis(phosphines) in constructing 'insulated' molecular wire models based on polyynediyl complexes, ${ }^{[23]}$ providing a conceptual basis for the work which follows. The pseudo-macrocyclic complex $\{\mathrm{RuCp}\}_{2}(\mu-\mathrm{C} \equiv \mathrm{CC} \equiv \mathrm{C})\left(\mu-\mathrm{Ph}_{2} \mathrm{P}\left(\mathrm{CH}_{2}\right)_{5} \mathrm{PPh}_{2}\right)_{2} \quad$ (2 Figure 4) was prepared in $33 \%$ yield by phosphine exchange of 1 with $1,5-$ bis(diphenylphosphino)pentane (Figure 5) and crystallographically characterized. ${ }^{[24]}$ Full spectroscopic and analytical data are given in the SI. The phosphine ligands constrain 2 to a narrow range of conformers with $\Omega$ being close to $0^{\circ}$ and thus should exhibit properties similar to those of cis-[1']

The IR and UV-vis-NIR spectra of $[2]^{+}$were obtained using the same spectroelectrochemical methods as employed for $[1]^{+}$(Figure 4 and SI). The $v(C \equiv C)$ band in $[2]^{+}\left(1858 \mathrm{~cm}^{-1}\right)$ is noticeably narrower than for [1] $]^{+}\left(1855 \mathrm{~cm}^{-1}\right)$, providing some evidence for restricted rotation in the tethered system. The NIR absorption bands in $[1]^{+}$(Figure 1) and $[2]^{+}$(Figure 4) are both clearly asymmetric, revealing the 
low-energy 'cut-off' associated with a strongly coupled system. ${ }^{[17,18]}$ However, the high-energy shoulder evident in $[\mathbf{1}]^{+}$(Figure 1) is substantially reduced in intensity in the conformationally restricted compound $[2]^{+}$(Figure 4). This observation is entirely in agreement with the TDDFT results for trans- $\left[1^{\prime}\right]^{+}$, cis- $-\left[1^{\prime}\right]^{+}$and perp- $\left[1^{\prime}\right]^{+}$.

Mixing of localized metal-based excitations, as featured in Meyer's model, ${ }^{[19]}$ is not applicable here (given the low spin-orbit coupling constant of $\mathrm{Ru}$ ) and cannot explain the high-energy shoulder. In addition, whilst fitting of the band shape by deconvolution in a series of Gaussian-shaped sub-bands is obviously possible, such fitting-based solutions do not, per se, reveal the electronic origin of the underlying excitations. Moreover, interpretations based on the number of sub-bands necessary for an accurate fit to the experimental data can be misleading in systems close to the localized/delocalized borderline due to the inherently asymmetric shape of the band (see discussion in Supporting Information).

A full optimization of $\left[2^{\prime}\right]^{+}$starting from a $C_{\mathrm{s}}$-symmetric structure led to a delocalized system with a P-Ru-Ru-P dihedral angle close to $0^{\circ}$, and a calculated $v(\mathrm{C} \equiv \mathrm{C})$ frequency of $1874 \mathrm{~cm}^{-1}$. TDDFT calculations give a single $\left(\pi-\pi^{*}\right)$ transition at $12012 \mathrm{~cm}^{-1}\left(\mu_{\text {trans }}=10.1 \mathrm{D}\right)$ occurring from the $\beta-\mathrm{HOMO}-1$ to $\beta$-SOMO excitation (Figure 6). The calculated band is slightly blue-shifted in comparison to cis-[1'] $]^{+}$ $\left(11572 \mathrm{~cm}^{-1}\right)$ whilst the experimental band maximum is observed at $11120 \mathrm{~cm}^{-1}$. The $\beta$-HOMO-3 to $\beta$-SOMO transition has negligible intensity for the tethered system $\left[2^{\prime}\right]^{+}$

In summary, the NIR band envelope observed for the simple diynediyl complex $[1]^{+}$features two transition envelopes with distinct electronic character $\left(\pi-\pi^{*}\right.$ and MLCT) arising from a distribution of conformers in solution. The observed NIR absorption profile of $[1]^{+}$is in good agreement with the predictions based on a relaxed 
rotamer scan and well-matched with the results from the three fully optimized

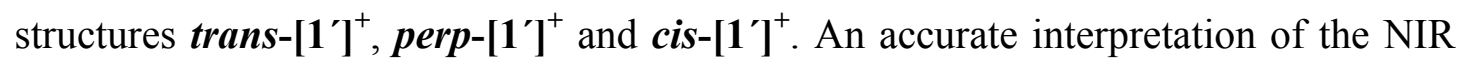
spectrum of $[\mathbf{1}]^{+}$must therefore allow for the different spectroscopic properties of the various rotameric forms. These conclusions likely apply to many other examples of 'mixed-valence' complexes with low axial symmetry and relatively free rotational elements. Detailed analyses of the NIR spectra of such systems should therefore consider not only the contributions to the band shape that can arise from vibronic coupling and transitions from lower-lying filled metal orbitals that gain intensity through low local coordination symmetry and/or spin orbit coupling but also the potential for rotamers with distinct spectroscopic profiles. The latter will not be adequately treated by interpretations drawn from a single lowest energy conformer.

\section{Experimental Section}

All ground-state structures and properties were obtained using a version of the TURBOMOLE 6.4 code $^{[25]}$ locally modified by the Kaupp group. Subsequent TDDFT calculations to gain excited-state properties were performed using Gaussian09. ${ }^{[26]}$ All unrestricted DFT calculations were performed with the global hybrid functional BLYP35 ${ }^{[20]}$ and a continuum solvent model $(\mathrm{DCM}, \varepsilon=8.93)$. The latter was the conductor-like-screening solvent model (COSMO) in TURBOMOLE $6.4^{[27]}$ and the CPCM version ${ }^{[28]}$ of the polarizable continuum (PCM) solvent model in Gaussian09. Split-valence basis sets def2-SVP and the associated Stuttgart effectivecore potentials for Ru were employed. ${ }^{[29]}$ Calculated harmonic vibrational frequencies were scaled by an empirical factor of $0.95 .^{[30]}$ Complex 1 was synthesized via a modified literature ${ }^{[5]}$ procedure. Complex 2 was synthesized by phosphine exchange of 1 with 1,5-bis(diphenylphosphino)pentane, and single crystals were obtained by 
slow evaporation from $\left[\mathrm{D}_{2}\right]-\mathrm{DCM}$. IR and UV-vis-NIR spectroelectrochemical experiments were carried out in a $0.1 \mathrm{M}$ solution of $\mathrm{NBu}_{4} \mathrm{PF}_{6}$ in $\mathrm{DCM}$ using an OTTLE cell. ${ }^{[31]}$ The crystallographic structure was solved by direct methods and refined by full-matrix least squares on $\mathrm{F}^{2}$ for all data using OLEX2 $2^{[32]}$ and SHELXTL ${ }^{[33]}$ software. All non-disordered non-hydrogen atoms were refined with anisotropic displacement parameters, $\mathrm{H}$-atoms were placed into calculated positions and refined in "riding" mode.

\section{Acknowledgements}

This work has been supported by the Berlin DFG cluster of excellence on "Unifying Concepts in Catalysis" (UniCat), by DFG project KA1187/13-1, and by the EPSRC. M. P. gratefully acknowledges the German Academic Exchange Service (DAAD) for a travel scholarship. P. J. L. holds an EPSRC Leadership Fellowship.

[1] M. I. Bruce, P. J. Low, Adv. Organomet. Chem. 2004, 50, 179.

[2] a) Q. Zheng, J. C. Bohling, T. B. Peters, A. C. Frisch, F. Hampel, J. A. Gladysz, Chem. Eur. J. 2006, 12, 6486; b) W. Mohr, J. Stahl, F. Hampel, J. A. Gladysz, Chem. Eur. J. 2003, 9, 3324; c) M. I. Bruce, K. A. Kramarczuk, B. W. Skelton, A. H. White, J. Organomet. Chem. 2010, 695, 469; d) M. I. Bruce, B. K. Nicholson, N. N. Zaitseva, C.R. Chemie 2009, 12, 1280; e) A. B. Antonova, M. I. Bruce, B. G. Ellis, M. Gaudio, P. A. Humphrey, M. Jevric, G. Melino, B. K. Nicholson, G. J. Perkins, B. W. Skelton, B. Stapleton, A. H. White, N. N. Zaitseva, Chem. Commun. 2004, 960; f) W. A. Chalifoux, R. R. Tykwinski, Nature Chem. 2010, 2, 967. 
[3] a) K. Costuas, S. Rigaut, Dalton Trans. 2011, 40, 5643; b) P. Aguirre-Etcheverry, D. O’Hare, Chem. Rev. 2010, 110, 4839; c) A. Ceccon, S. Santi, L. Orian, A. Bisello, Coord. Chem. Rev. 2004, 248, 683.

[4] a) P. J. Low, Dalton Trans. 2005, 2821; b) F. Paul, C. Lapinte, Coord. Chem. Rev. 1998, 178, 431; c) S. Ballmann, W. Hieringer, S. Secker, Q. Zheng, J. A. Gladysz, A. Gorling, H. B. Weber, ChemPhysChem 2010, 11, 2256; d) K. Venkatesan, O. Blaque, H. Berke, Dalton Trans. 2007, 1091.

[5] E. C. Fitzgerald, N. J. Brown, R. Edge, M. Helliwell, H. N. Roberts, F. Tuna, A. Beeby, D. Collison, P. J. Low, M. W. Whiteley, Organometallics 2012, 31, 157.

[6] J. F. Halet, C. Lapinte, Coord. Chem. Rev. 2013, 257, 1584.

[7] N. Le Narvor, L. Toupet, C. Lapinte, J. Am. Chem. Soc. 1995, 117, 7129.

[8] M. I. Bruce, P. J. Low, K. Costuas, J. F. Halet, S. P. Best, G. A. Heath, J. Am. Chem. Soc. 2000, 122, 1949.

[9] M. I. Bruce, B. G. Ellis, P. J. Low, B. W. Skelton, A. H. White, Organometallics 2003, 22, 3184

[10]M. I. Bruce, K. Costuas, T. Davin, J. F. Halet, K. A. Kramarczuk, P. J. Low, B. K. Nicholson, G. J. Perkins, R. L. Roberts, B. W. Skelton, M. E. Smith, A. H. White, Dalton Trans. 2007, 5387.

[11] a) M. Brady, W. Q. Weng, Y. L. Zhou, J. W. Seyler, A. J. Amoroso, A. M. Arif, M. Bohme, G. Frenking, J. A. Gladysz, J. Am. Chem. Soc. 1997, 119, 775; b) H. J. Jiao, K. Costuas, J. A. Gladysz, J. F. Halet, M. Guillemot, L. Toupet, F. Paul, C. Lapinte, J. Am. Chem. Soc. 2003, 125, 9511. 
\begin{tabular}{lllllll}
\hline$[12] P$. & J. & Low, & S. & Bock, & Electrochim.
\end{tabular} http://dx.doi.org/10.1016/j.electacta.2013.01.143.

[13] a) P. Belanzoni, N. Re, A. Sgamellotti, C. Floriani, J. Chem. Soc., Dalton Trans. 1998, 1825; b) F. Zhuravlev, J. A. Gladysz, Chem. Eur. J. 2004, 10, 6510.

[14]F. J. Fernandez, K. Venkatesan, O. Blaque, M. Alfonso, H. W. Schmalle, H. Berke, Chem. Eur. J. 2003, 9, 6192.

[15]a) F. Paul, W. E. Meyer, L. Toupet, H. J. Jiao, J. A. Gladysz, C. Lapinte, J. Am. Chem. Soc. 2000, 122, 9405; b) F. Coat, M. A. Guillevic, L. Toupet, F. Paul, C. Lapinte, Organometallics 1997, 16, 5988.

[16] a) M. H. Chisholm, B. J. Lear, Chem. Soc. Rev. 2011, 40, 5254; b) B. J. Lear, M. H. Chisholm, Inorg. Chem. 2009, 48, 10954.

[17] a) C. Creutz, Prog. Inorg. Chem., 1983, 30, 1; b) B. S. Brunschwig, C. Creutz, N. Suttin, Chem. Soc. Rev. 2002, 31, 168; c) D. M. D'Alessandro, F. R. Keene, Chem. Soc. Rev. 2006, 35, 424.

[18] a) A. Heckman, C. Lambert, Angew. Chem. Int. Ed. 2012, 51, 326; b) S. F. Nelson, M. N. Weaver, J. P. Telo, J. Phys. Chem. A 2007, 111, 10993; c) S. F. Nelson, A. E. Konradsson, M. N. Weaver, J. P. Telo, J. Am. Chem. Soc. 2003, $125,12493$.

[19]K. D. Demadis, C. M. Hartshorn, T. J. Meyer, Chem. Rev. 2001, 101, 2655.

[20]a) M. Renz, K. Theilacker, C. Lambert, M. Kaupp, J. Am. Chem. Soc. 2009, 131, 16292; b) M. Kaupp, M. Renz, M. Parthey, M. Stolte, F. Würthner, C. Lambert, Phys. Chem. Chem. Phys. 2011, 13, 16973. 
[21]a) M. I. Bruce, B. G. Ellis, M. Gaudio, C. Lapinte, G. Melino, F. Paul, B. W. Skelton, M. E. Smith, L. Toupet, A. H. White, Dalton Trans. 2004, 1601; b) M. I. Bruce, B. C. Hall, B. D. Kelly, P. J. Low, B. W. Skelton, A. H. White, J. Chem. Soc., Dalton Trans. 1999, 3719; c) M. I. Bruce, P. Hinterding, E. R. T. Tiekink, B. W. Skelton, A. H. White, J. Organomet. Chem. 1993, 450, 209.

[22]M.I. Bruce, K. Costuas, B.G. Ellis, J.-F. Halet, .J. Low, B. Moubaraki, K.S. Murray, N. Ouddai, G.J. Perkins, B.W. Skelton, A.H. White, Organometallics 2007, 26, 3735 .

[23] a) J. Stahl, W. Mohr, L. de Quadras, T. B. Peters, J. C. Bohling, J. M. MartinAlvarez, G. R. Owen, F. Hampel, J. A. Gladysz, J. Am. Chem. Soc. 2007, 129, 8282; b) L. de Quadras, E. B. Bauer, W. Mohr, J. C. Bohling, T. B. Peters, J. M. Martin-Alvarez, F. Hampel, J. A. Gladysz, J. Am. Chem. Soc. 2007, 129, 8296.

[24] Crystal data for 2: $\mathrm{C}_{72} \mathrm{H}_{70} \mathrm{P}_{4} \mathrm{Ru}_{2} \times 4.5 \mathrm{CH}_{2} \mathrm{Cl}_{2}, M=1643.47$, monoclinic, space group $\mathrm{P} 2{ }_{1}, a=13.5567(5), b=19.2602(7), c=14.6134(5) \AA, \beta=103.999(1)^{\circ}, V$ $=3702.3(2) \AA^{3}, Z=2, \mu(\mathrm{MoK} \alpha)=0.862 \mathrm{~mm}^{-1}, D_{\text {calc }}=1.474 \mathrm{~g} / \mathrm{mm}^{3}(\lambda \mathrm{Mo}-\mathrm{K} \alpha, \lambda$ $=0.71073 \AA), \mathrm{T}=120(1) \mathrm{K} .46187$ reflections $\left(3.56 \leq 2 \theta \leq 58^{\circ}\right)$ were collected on a Bruker SMART-CCD 6000 diffractometer yielding 19665 unique data ( $\mathrm{R}_{\text {merg }}$ $=0.0514)$. Final conventional $R_{1}(F)=0.0508$ for 16176 reflections with $\mathrm{I} \geq 2 \sigma$, $\mathrm{wR}_{2}\left(\mathrm{~F}^{2}\right)=0.1334$ for all data (831 refined parameters), $\mathrm{GOF}=1.034$. The largest peak on the residual map $\left(1.44 \mathrm{a} / \AA^{3}\right)$ is located in the vicinity of disordered $\mathrm{Cl}$ atom of DCM solvent molecule. Crystallographic data for the structure have been deposited with the Cambridge Crystallographic Data Centre as supplementary publication CCDC-929707. 
[25]TURBOMOLE V6.4 2012, a development of University of Karlsruhe and Forschungszentrum Karlsruhe GmbH, 1989-2007, TURBOMOLE GmbH, since 2007.

[26] Gaussian 09, revision A.02, M. J. Frisch, et al., Gaussian, Inc., Wallingford, CT, 2009.

[27]A. Klamt, G. Schüürmann, J. Chem. Soc., Perkin Trans. 2 1993, 5, 799.

[28] a) V. Barone, M. Cossi, J. Phys. Chem. A 1998, 102, 1995; b) M. Cossi, N. Rega, G. Scalmani, V. Barone, J. Comput. Chem. 2003, 24, 669.

[29]a) A. Schäfer, H. Horn, R. Ahlrichs, J. Chem. Phys. 1992, 97, 2571; b) F. Weigend, R. Ahlrichs, Phys. Chem. Chem. Phys. 2005, 7, 3297; c) D. Andrae, U. Häussermann, M. Dolg, H. Stoll, H. Preuss, Theor. Chim. Acta 1990, 77, 123.

[30]a) A. P. Scott, L. Radom, J. Phys. Chem. 1996, 100, 16502; b) J. C. Roder, F. Meyer, I. Hyla-Kryspin, R. F. Winter, E. Kaifer, Chem. Eur. J. 2003, 9, 2636.

[31]M. Krejčík, M. Daněk, F. J. Hartl, Electroanal. Chem. 1991, 317, 179.

[32] O. V. Dolomanov, L. J. Bourhis, R. J. Gildea, J. A. K. Howard, H. Puschmann, J. Appl. Cryst. 2009, 42, 339.

[33] G. M. Sheldrick, Acta. Cryst. 1990, A46, 467. 
Figure captions

Figure 1. NIR spectra collected during spectroelectrochemical oxidation of $\left[\left\{\mathrm{Ru}\left(\mathrm{PPh}_{3}\right)_{2} \mathrm{Cp}\right\}_{2}(\mu-\mathrm{C} \equiv \mathrm{CC} \equiv \mathrm{C})\right][1]$ to $[1]^{+}$in $\mathrm{DCM} / 0.1 \mathrm{M} \mathrm{NBu}_{4} \mathrm{PF}_{6}$, illustrating the shoulder on the high-energy side of the band.

Figure 2. Isosurface plots ( \pm 0.03 a.u.) of the $\beta$-SOMO (top) and $\beta$-HOMO-1 (bottom) of trans-[1'] $]^{+}$(see Supporting Information for orbital labelling details).

Figure 3. Isosurface plot ( \pm 0.03 a.u.) of the $\beta$-HOMO-3 of perp-[1'] $]^{+}$.

Figure 4. NIR spectra collected during spectroelectrochemical oxidation of $\left[\{\mathrm{RuCp}\}_{2}(\mu-\mathrm{C} \equiv \mathrm{CC} \equiv \mathrm{C})\left(\mu-\mathrm{PPh}_{2}\left(\mathrm{CH}_{2}\right)_{5} \mathrm{PPh}_{2}\right)_{2}\right][2]$ to $[2]^{+}$in $\mathrm{DCM} / 0.1 \mathrm{M}$ $\mathrm{NBu}_{4} \mathrm{PF}_{6}$. Note the loss of the shoulder on the high energy side of the band.

Figure 5. A plot of a molecule of 2, with H-atoms omitted for clarity. Selected bond lengths $(\AA)$ and angles $\left({ }^{\circ}\right)$ : Ru1-C1 2.011(4), C1-C2 1.216(6), C2-C3 1.384(6), C3C4 1.219(6), C4-Ru2 2.009(4); Ru1-C1-C2 174.0(4), C1-C2-C3 170.7(5), C2-C3C4 170.7(5), C3-C4-Ru2 174.6(4).

Figure 6. Isosurface plot ( \pm 0.03 a.u.) of the $\beta-\mathrm{HOMO}-1$ of $\left[\mathbf{2}^{\prime}\right]^{+}$. 


\section{Table of Contents}

Spinning Classes to Improve Your (Band) Shape: A blend of theoretical and experimental work demonstrates that the rotational conformation of mixed-valence complexes influences the low-energy (NIR) transitions in such molecules. Interpretations of the NIR band shapes are presented.

Keywords: mixed-valence complex $\cdot$ rotamer $\cdot$ NIR band shape $\cdot$ density functional calculations $\cdot$ electron transfer 